\title{
Hot European Summers and the Role of Soil Moisture in the Propagation of Mediterranean Drought
}

\author{
MATTEO ZAMPIERI* AND FABIO D'ANDREA
}

LMD/IPSL, Ecole Normale Supérieure, Paris, France

\author{
Robert Vautard, Philippe Ciais, Nathalie de Noblet-Ducoudré, and Pascal Yiou
}

LSCE/IPSL, Laboratoire CEA/CNRS/UVSQ, Gif sur Yvette, France

(Manuscript received 9 April 2008, in final form 1 April 2009)

\begin{abstract}
Drought in spring and early summer has been shown to precede anomalous hot summer temperature. In particular, drought in the Mediterranean region has been recently shown to precede and to contribute to the development of extreme heat in continental Europe. In this paper, this mechanism is investigated by performing integrations of a regional mesoscale model at the scale of the European continent in order to reproduce hot summer inception, starting with different initial values of soil moisture south of $46^{\circ} \mathrm{N}$. The mesoscale model is driven by the large-scale atmospheric conditions corresponding to the 10 hottest summers on record from the European Climate Assessment dataset. A northward progression of heat and drought from late spring to summer is observed from the Mediterranean regions, which leads to a further increase of temperature during summer in temperate continental Europe. Dry air formed over dry soils in the Mediterranean region induces less convection and diminished cloudiness, which gets transported northward by occasional southerly wind, increasing northward temperature and vegetation evaporative demand. Later in the season, drier soils have been established in western and central Europe where they further amplify the warming through two main feedback mechanisms: 1) higher sensible heat emissions and 2) favored upper-air anticyclonic circulation. Drier soils in southern Europe accelerate the northward propagation of heat and drying, increasing the probability of strong heat wave episodes in the middle or the end of the summer.
\end{abstract}

\section{Introduction}

The unprecedented heat wave witnessed during the summer of 2003 reached an amplitude of five standard deviations in some areas of Europe, according to the current surface temperature climatology. It triggered considerable concern in Europe because it was suggested to be a possible premonitory picture of a warmer European summer climate to come at the second half of the twenty-first century (Schär et al. 2004; Beniston 2004). Heat waves have been studied for a long time (e.g., Chang and Wallace 1987); also because of their severity in the south-central United States, several re-

\footnotetext{
* Current affiliation: ISAC-CNR, Lecce, Italy.
}

Corresponding author address: Fabio D'Andrea, LMD/IPSL, Ecole Normale Supérieure, 24 Rue Lhomond, 75005 Paris, France. E-mail: dandrea@lmd.ens.fr search studies have tried to provide a better understanding of their causes (Huang et al. 1996).

Heat waves over Europe are associated with anticyclonic weather regimes. Although the dynamics of the atmosphere at the intraseasonal low-frequency variability are mainly internal, a regime's occurrence can partially be favored by a number of external forcing processes. For example, Rossby wave trains originating from sea surface temperature anomalies in the tropical Atlantic have been shown to favor anticyclonic regimes in Europe (Cassou et al. 2005), favoring heat and drought. However, forcing by synoptic-scale conditions is not the only cause of heat waves (Della Marta et al. 2006). It was recently shown that several positive regional land surface feedbacks concur to amplify summer high temperatures. Fischer et al. (2007a,b) analyzed the soil-atmosphere feedbacks during the four hottest recent summers. In summer, a dry soil induces fewer clouds, which in turn increases the amount of incident solar energy at the surface and further enhances heat 
fluxes and the ratio of sensible over latent heat fluxes (Bowen ratio). This causes a positive feedback to soil drying. A drier soil additionally favors the development of anticyclonic circulation anomalies by increasing the thickness of the lower layer of the troposphere (Ferranti and Viterbo 2006). Feudale and Shukla (2007) also suggested that warmer sea surface temperatures in the Mediterranean Sea can reinforce the anticyclonic circulation over central Europe. The role of the ocean, rather than supplying humidity to the continent, is therefore that of favoring anticyclonic regimes, and hence heating and limiting moisture influx (Black et al. 2004). These feedbacks then reinforce the drought in return. In the recent four hottest European summers, they were found to explain most of the heat anomaly (Fischer et al. 2007a). They are predicted to amplify the summertime climate variability over Europe in the future (Seneviratne et al. 2006).

Although soil moisture at the beginning of the summer is identified as a key factor controlling the summer mean temperature (D'Andrea et al. 2006), little is known about the underlying processes. Vautard et al. (2007) observed that, on average, the 10 hottest European summers since 1948 were systematically preceded by a winter and spring precipitation deficit over southern Europe. This indicates that hot summers can occur even after normal or wet winter and spring conditions in the north, provided that drier soils prevailed in the south. This controlling role of southern soil moisture was tentatively explained by a northward progression of drought and heat carried by southerly wind episodes. However, Vautard et al. (2007) neither separate nor quantify the relative importance of each process involved in the northward progression of drought in detail. In the present article, the fifth-generation Pennsylvania State University (PSU)-National Center for Atmospheric Research (NCAR) Mesoscale Model (MM5; Dudhia 1993) is adapted and used to investigate the mechanisms that link summer droughts and heat waves in central Europe to their preceding precursor winter and spring rainfall deficits in Mediterranean areas. Using this regional modeling framework, we modeled the inception of the 10 hottest summers of the past 50 years.

A better understanding of the role of spring moisture in Mediterranean soils in determining the summer European heat waves occurrence is crucial for the future, because climate model simulations for the end of the twenty-first century all indicate that regional summer drought (or the area affected by drought) should increase.

Section 2 presents the MM5 simulation's setup and results, evaluates them against observations from the Climate Research Unit dataset (Mitchell and Jones 2005), and discusses the soil moisture initialization of the sensi-

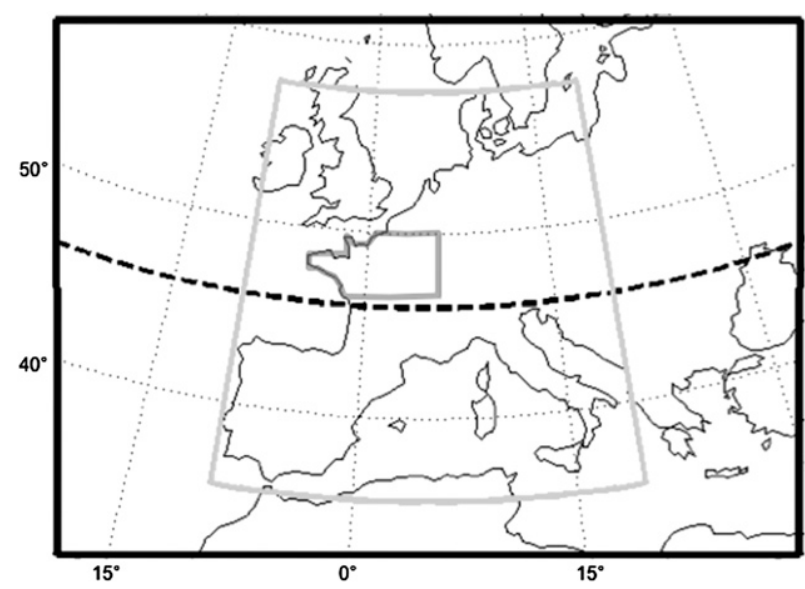

FIG. 1. Model domain. The dashed line marks $46^{\circ} \mathrm{N}$. The gray square is the region on which most of the diagnostics will be shown below. The small gray region is the area of integration for northern France. See text for details.

tivity experiments. Section 3 describes the model sensitivity experiment's results, analyzing the effect of idealized changes in the Mediterranean soil moisture. In section 4 we discuss the results and draw some conclusions.

\section{Model simulations}

\section{a. Model configuration}

Control and sensitivity simulations are carried out using MM5. The model domain is centered at $47.5^{\circ} \mathrm{N}$, $5^{\circ} \mathrm{E}$ (see Fig. 1), with a Lambert-conformal grid composed of $125 \times 85$ points, with a resolution of $36 \mathrm{~km}$. Vertical representation of the meteorological variables uses a grid with 23 layers, with a majority of layers below $2500 \mathrm{~m}$, in order to better resolve boundary layer processes. Simulations use the 3.7.3 model version with Reisner microphysics, a Kain-Fritsch convection scheme, a Medium-Range Forecast (MRF) PBL boundary layer scheme, and Community Climate Model, version 2 (CCM2) radiation scheme. The Noah land surface scheme is used (Ek et al. 2003). Noah uses four soil layers (10-, 30-, 60-, and 100-cm thick, from top to bottom) to compute soil temperature, soil water/ice, and snow cover. The total soil depth is $2 \mathrm{~m}$, with the root zone in the upper $1 \mathrm{~m}$ of the soil. In addition to the sensible and radiative heat fluxes, the Noah surface scheme accounts for the evapotranspiration flux from the vegetation, given a soil and hydraulic model for moisture supply to the plant roots. The canopy in Noah exchanges heat and moisture as a single "big leaf." Sensible and latent heat fluxes are determined through a coupling between radiation and photosynthesis models and the solution of a leaf energy balance; the Penman-Monteith (Mahrt and 
Ek 1984) resistance method is adopted. The model uses the observed distribution of 24 vegetation/land use types according to U.S. Geological Survey (USGS) classification and the distribution of nine soil classes categories (Zobler 1986).

The MM5 domain size is relatively large to allow for an unconstrained evolution of regional circulation anomalies in response to local surface forcing anomalies. Maps of the responses will be shown in a smaller region, including most of Europe, marked in gray in Fig. 1. Initial and boundary conditions use the global analyses issued from the National Centers for Environmental Prediction (NCEP)-NCAR reanalyses (Kalnay 1996).

\section{b. Simulations design}

We simulated the evolution of regional weather from spring to early summer during each of the 10 hottest summers since 1948, as identified in Vautard et al. (2007). These summers are 1950, 1952, 1959, 1964, 1976, 1983, 1992, 1994, 1995, and 2003. Their characteristics are presented and discussed in the supplementary online material of Vautard et al. (2007). The summers were chosen based on their average June-August mean daily maximum temperature over about 100 stations in Europe.

Initialization simulations (INI) are performed starting at 0000 UTC 1 April and ending at 0000 UTC 1 June to produce soil moisture fields for the initial conditions of the sensitivity simulations starting at 0000 UTC 1 June. This is motivated by the fact that reanalyzed soil moisture strongly depends on the model by which this field is produced, especially because of the lack of data. Errors in the analyzed fields are found in the case, for instance, of the European Centre for Medium-Range Weather Forecasts (ECMWF) analysis data product, where the soil moisture seasonal cycle is known to be underestimated (Ferranti and Viterbo 2006). Our initialization procedure guarantees that the soil moisture field is consistent with MM5 physics parameterization and that it is in equilibrium with the atmosphere to avoid initial transients that could last for the entire duration of the sensitivity simulations and modify the results.

Sensitivity simulations cover the summer heat wave inception, starting on at 0000 UTC 1 June and ending at 0000 UTC August 7, when we suppose that the drought is well established over continental Europe. The following three simulations are performed: a control simulation (CTR), where the initial soil moisture field is taken from the INI simulations detailed previously, and two sensitivity simulations, where initial soil moisture is arbitrarily set to either drier or wetter conditions than those in CTR in southern European areas (everywhere south of $46^{\circ} \mathrm{N}$ ). This southern boundary was made of regions that were suggested by Vautard et al. (2007, see their figure in the supplementary material) to be the critical for inducing summer heat in continental Europe. Initially dry simulations (referred to as DRY hereafter) prescribe initial southern volumetric soil moisture of $15 \%$, while initially wet simulations (referred to as WET hereafter) prescribe a value of $30 \%$. These two settings correspond, respectively, to the near-wilting point and near saturation for most of the southern region. While in central Spain, as well as in the southern part of Italy and the Balkans, the conditions of the soil are almost always dry at the beginning of the summer; in the intermediate region lying between $44^{\circ}$ and $46^{\circ} \mathrm{N}$ there is a remarkable interannual variability. We estimated this variability (not shown), making use of the dataset of Fan and Van den Dool (2004), who forced a leaky-bucket model of soil with a long historical series of weather station data. The anomalies prescribed as DRY and WET correspond to one standard deviation in southern France and the northern part of Italy and the Balkans. Farther south, conversely, the WET simulation would constitute a rarer event. Note that these initial soil moisture contents are prescribed to the four soil layers. Initializing deep layers in that manner guarantees the long memory of the moisture anomaly [see, e.g., a comparison of the effect of soil moisture initialization at different levels in Ferranti and Viterbo (2006)]. Over continental areas north of $46^{\circ} \mathrm{N}$, the WET and DRY simulations are initialized by the same soil moisture as that in the CTR simulation.

\section{c. Model and observed summer climate}

To understand whether the model is able to simulate the high temperatures of the hot summers, the INI and CTR simulation results of daily maximal temperature, estimated from the 3-hourly outputs, are compared to the gridded meteorological datasets of monthly averaged maximum temperature of the Climate Research Unit, version TS 2.10 (Mitchell and Jones 2005). Figure 2 shows the monthly means of maximum daily surface temperature averaged over all of the hot summers except 2003, for April-July; 2003 is not included in the TS 2.10 dataset. Results shown hereafter are for a subregion of the domain, from $35.5^{\circ}$ to $57.5^{\circ} \mathrm{N}$, and from $9.5^{\circ} \mathrm{E}$ to $19.5^{\circ} \mathrm{W}$ (see Fig. 1 above).

The model has an overall cold diurnal temperature bias that has already been identified and investigated (Zhong et al. 2005; Fernández et al. 2007). It results from a complex combination of parameterization shortcomings, among which a major role is played in summer by an excess of soil moisture. The bias is composed of dipolar structures associated with orographic features, and it is also spread over all of central Europe, reaching maximum values of $5^{\circ} \mathrm{C}$ in this region, especially in May. 

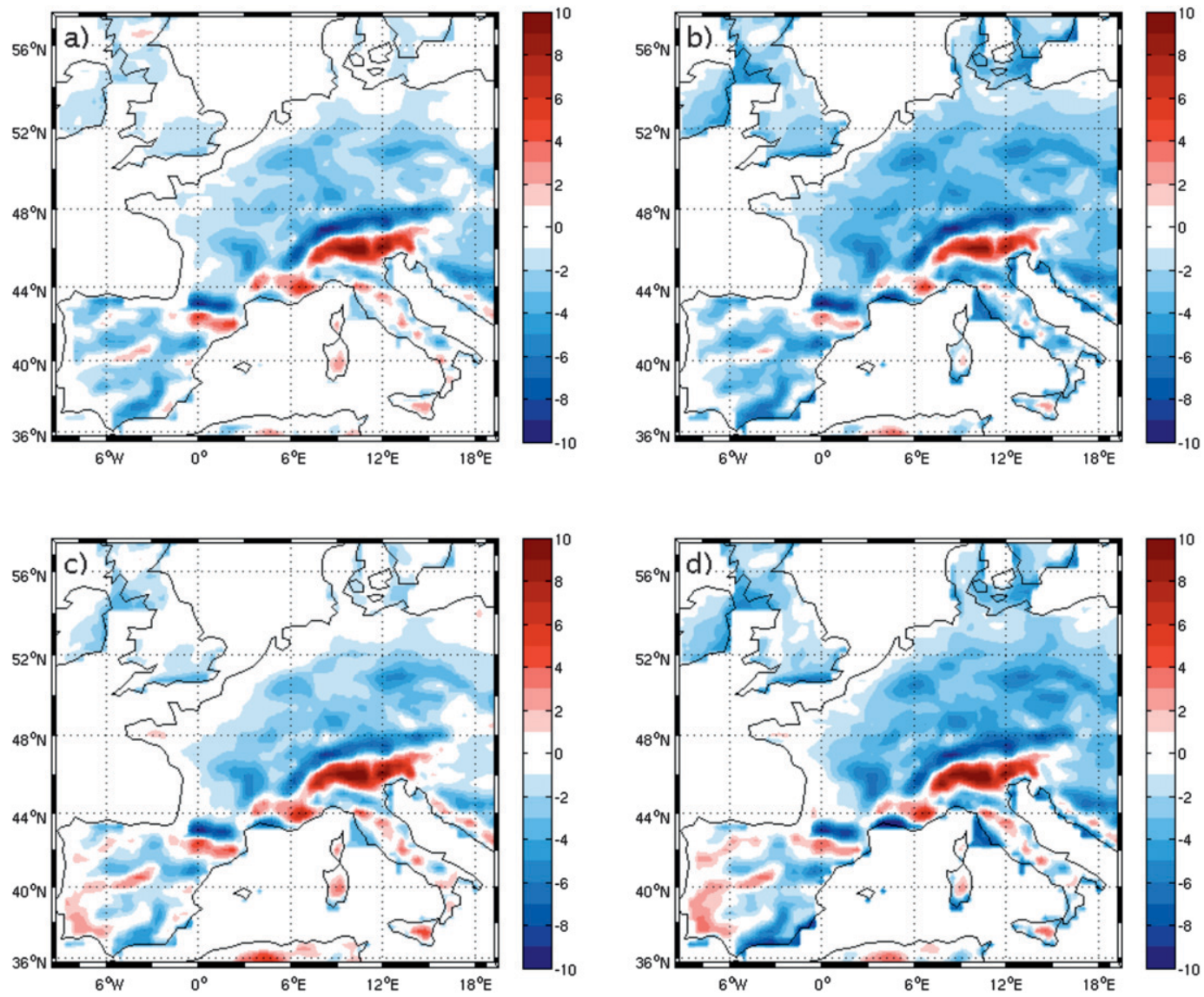

FIG. 2. Difference between simulated (INI and CTR) and observed (CRU) 2-m maximum temperature monthly means averaged over on all summers except 2003: (a) April, (b) May, (c) June, and (d) July.

The bias is minimal in June. This result is systematic over all of the summers; in fact, the standard deviation of the difference field (not shown) is lower than $1^{\circ} \mathrm{C}$ in April-June, and reaches $1^{\circ} \mathrm{C}$ only in July. The MM5 temperature bias can prevent soils from drying sufficiently in the early part of the summer, with the consequence that the soil-atmosphere feedback is underestimated. We shall keep this in mind in the interpretation of the results below.

\section{d. Soil moisture initialization}

Figure 3 shows the difference of the soil moisture produced by the INI simulations at 0000 UTC 1 June that is used to initialize the CTR, DRY, and WET simulations, and the corresponding soil moisture from the ECMWF reanalysis. Latter values are plotted after interpolation to the model soil layer and integration over the root layer, which here is defined as the first meter of soil close to the surface.

Soil moisture on 1 June produced by the INI simulations is significantly different from that of the reanalysis. The modeled soil is drier than that from the ECMWF reanalysis, especially at the coasts, where more than $10 \%$ of the difference of total soil moisture content is reached. Positive values of the MM5 minus ECMWF differences may be found inland, sometimes related to the orography. Positive differences are almost always lower than $10 \%$. On average, over the domain showed in Fig. 3, the model is $2 \%$ drier than the reanalysis for the total soil volume.

\section{Impact of initial soil moisture in southern Europe}

The objective of this section is to examine the differences between the DRY and WET simulations, in order to understand the impact of drought in southern Europe in determining a northward propagation and establishment of hot and dry summers.

\section{a. Impact on 2-m temperature}

Figures $4 \mathrm{a}, \mathrm{b}$ show the $2-\mathrm{m}$ temperature differences at 1500 UTC between the DRY and WET simulations (DRY minus WET) averaged over the month of July and the first 7 days of August (hereafter simply referred 

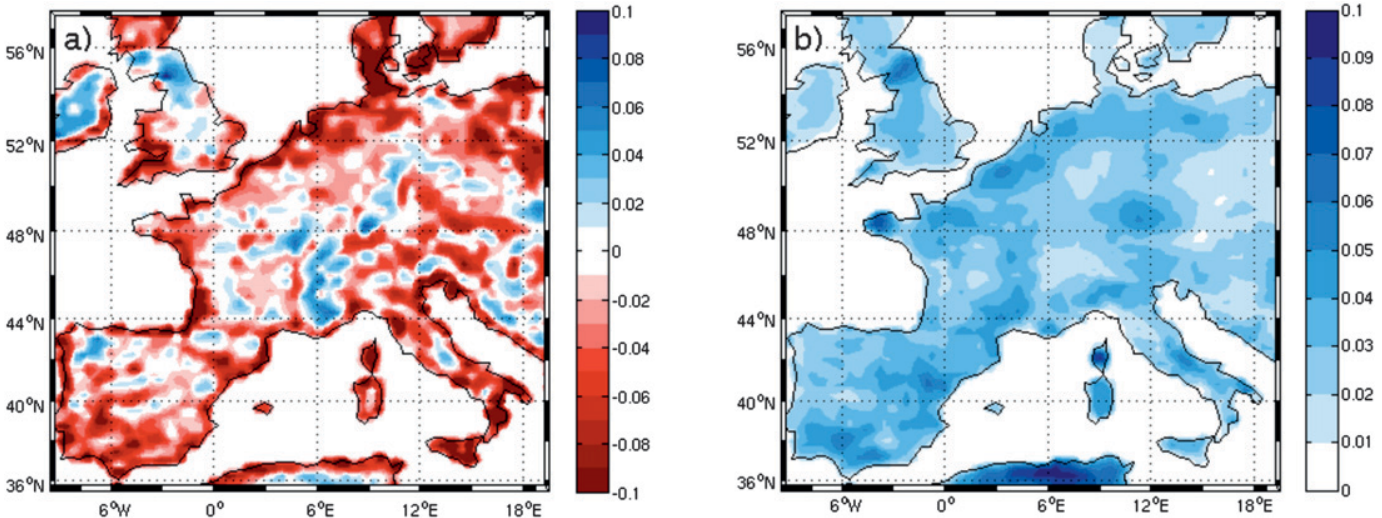

FIG. 3. (a) INI integrations minus NCEP-NCAR reanalysis differences of root soil moisture at 0000 UTC 1 Jun for April-May, in a fraction of the total soil volume. (b) The corresponding standard deviation.

as "July"), together with the difference between July and June of the same DRY minus WET difference. These figures isolate the anomaly evolution independently of the initial condition.
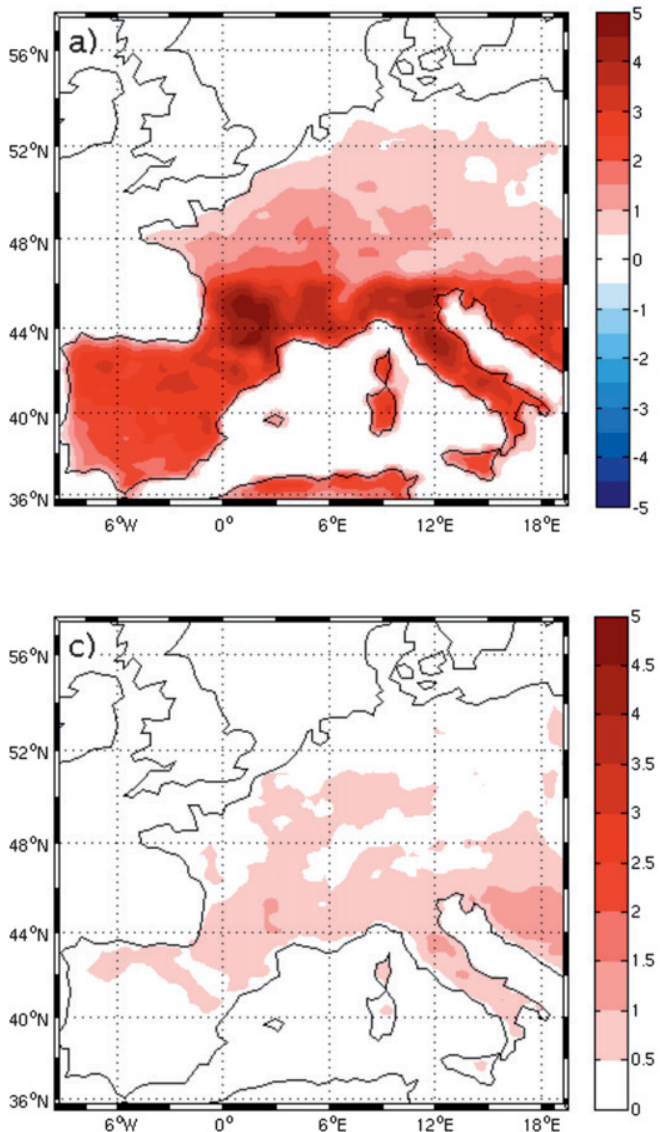

South of $46^{\circ} \mathrm{N}$ where the initial soil moisture is altered in DRY and WET, the 2-m temperature response is strong, on average, about $2^{\circ}-5^{\circ} \mathrm{C}$, and almost immediate (the same anomaly is also found in the June difference
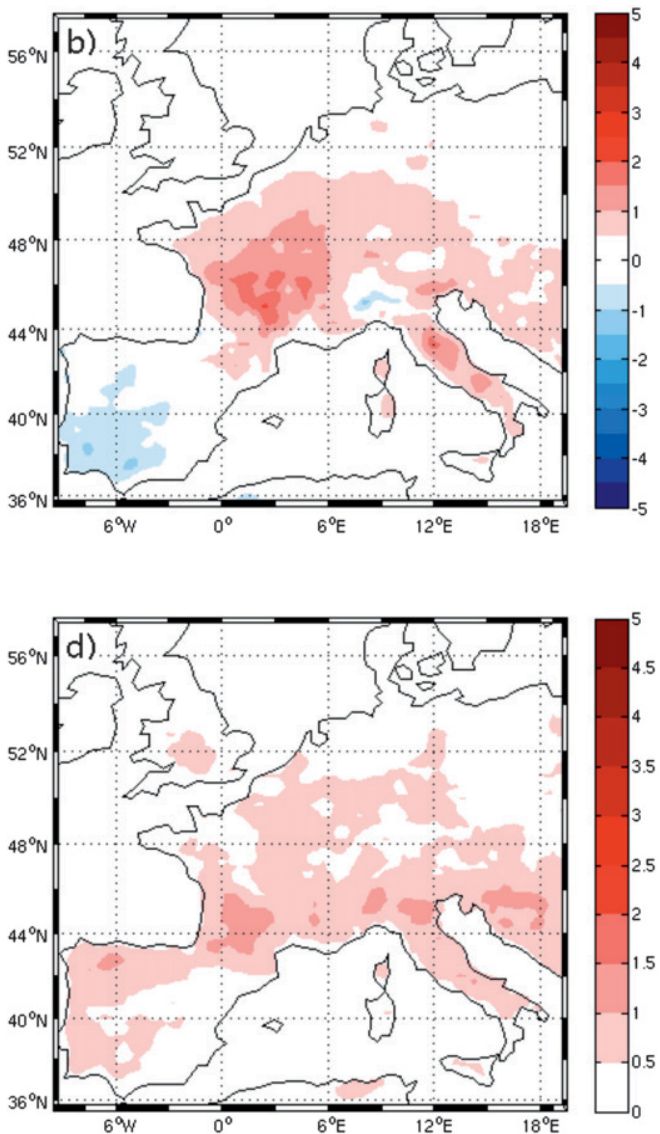

FIG. 4. Results from the sensitivity (DRY and WET) simulations averaged over the 10 hottest summers of the last 50 years: (a) difference (DRY minus WET) of 1500 UTC 2-m temperature averaged over the month of July; (b) difference of July minus June of the DRY minus WET field at 1500 UTC for 2-m temperature (an increment of the DRY - WET differences). (c),(d) Temperature (interannual) standard deviation across the 10 individual summers of the variables plotted in (a) and (b), respectively. 
maps, not shown). Farther north, in the $46^{\circ}-50^{\circ} \mathrm{N}$ band, the air is also relatively warmer in DRY but the difference is weaker than farther south $\left(0.5^{\circ}-1.5^{\circ} \mathrm{C}\right)$. Moreover, most of the temperature response at these latitudes is found during the second month of simulation. Thus, a delay of 1 month is necessary for the northward progression of heat to be established. These figures are in agreement with the former simulation carried out by Vautard et al. (2007) for the sole summer of 1994, but with an amplitude that is approximately $1^{\circ} \mathrm{C}$ lower. The differences shown in Fig. 4 pass a 95\% statistical confidence test practically everywhere.

The intensity of the temperature anomaly progression exhibits large differences from year to year among the 10 hot summers investigated. The standard deviation computed over the 10 summers (Figs. 4c,d) lies around $0.5^{\circ} \mathrm{C}$, which is of the same order of magnitude of the signal north of $46^{\circ} \mathrm{N}$. For the summers of 1959 and 1983 , almost no significant signal is found north of $46^{\circ} \mathrm{N}$; these two summers are discussed further below.

The time evolution of the mean DRY minus WET temperature differences integrated over the target area of northern France, comprised between $46.5^{\circ}$ and $50^{\circ} \mathrm{N}$, and between the Atlantic coast and $6^{\circ} \mathrm{E}$ (see gray region in Fig. 1), is shown in Fig. 5. During the first month the DRY minus WET temperature difference remains well below $1^{\circ} \mathrm{C}$. It increases during July, up to around $2^{\circ} \mathrm{C}$. However, a large variability from year to year is also observed, as shown by the standard deviation.

\section{b. Impact on precipitation}

Figures $6 \mathrm{a}, \mathrm{b}$ shows the DRY - WET total accumulated precipitation difference and its July minus June difference. Much of the rainfall change is found south of $46^{\circ} \mathrm{N}$, and is almost equally distributed between the first and the second month of the simulations, except over orography. The largest differences (up to $8 \mathrm{~cm}$ in absolute value, corresponding to $50 \%$ of the mean precipitation in CTR) are found over mountainous areas, where maximal cumulated precipitation is also located, resulting from orographic convection (Fig. 6). Drier soils in the south thus inhibit diurnal convection development. This inhibition also seems to propagate to the northern part of the domain in the Alps, and toward central and northern France. The precipitation anomaly starts in June and it is reinforced in July, as seen in Fig. 6b.

The relative interannual variability of precipitation DRY minus WET anomaly is higher than that of 2-m temperature, as Figs. $6 \mathrm{c}, \mathrm{d}$ show, because it is much more dependent on the circulation that characterizes each singular summer. However, the zero-mean change hypothesis in the overall precipitation anomaly (Fig. 6a) can be rejected with a confidence of $95 \%$ up to $48^{\circ} \mathrm{N}$ in lati-

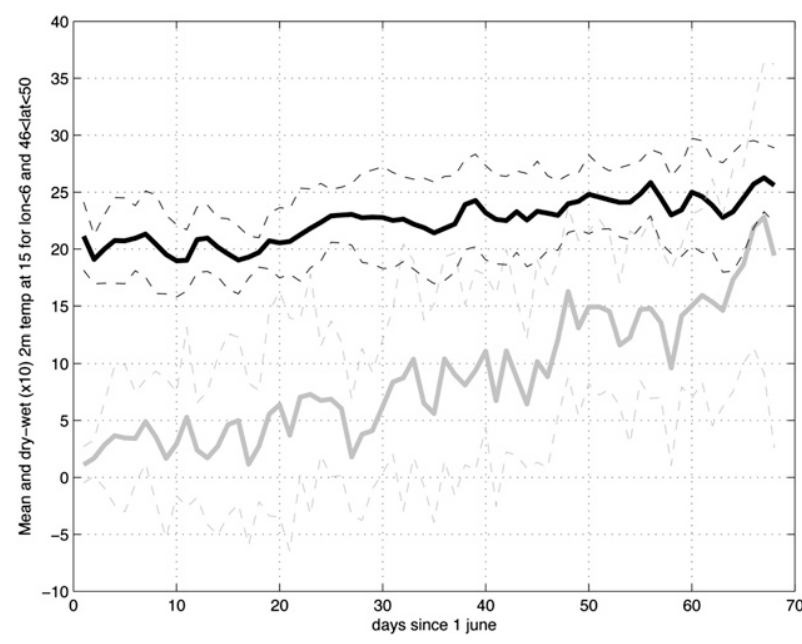

FIG. 5. Average time evolution over the 10 hottest summers of 2-m temperature at 1500 UTC averaged between $46.5^{\circ}$ and $50^{\circ} \mathrm{N}$ and for longitude between the Atlantic coast and $6^{\circ} \mathrm{E}$. The mean of DRY and WET results is in black, and the difference is in grey. The dashed lines represent the corresponding $1 \mathrm{std}$ dev bands. The difference is multiplied by 10 .

tude and $6^{\circ} \mathrm{E}$ in longitude. The July anomaly amplification showed in Fig. 6b is statistically significant in central France. Inspection of individual summer simulations (not shown) reveals important differences in precipitation that also extend farther in the northeast, but these differences remain highly variable. When we compare two integrations of the same summer (DRY and WET), convective precipitation events are in general produced at the same time and at the same location in WET and DRY, but they are less intense in the DRY case.

The time evolution of the DRY minus WET total accumulated precipitation in northern France (the same "target" area as in Fig. 5) for individual summers and their mean is shown in Fig. 7. The DRY minus WET accumulated precipitation difference is negative starting in June over northern France for all selected summers, except for years 1959 and 1992. In 1959, however, the difference is positive between day 20 and day 40, resulting from convective events associated with a frontal system of Atlantic origin that affects northern Spain and southern France in the WET simulation, while they get deflected to central and northern France in the DRY one, because of the more intense anticyclonic condition. On day 40 the same occurs over northern France and southern England, producing the opposite effect over the continent. In 1992, on day 5, a convective event, favored by a low pressure system located over central Europe, occurs north of the Alps and hits the target area in the DRY simulation, whereas it is slightly shifted to the east and misses the target area in the WET simulation. Apart from these two particular events, in all other 

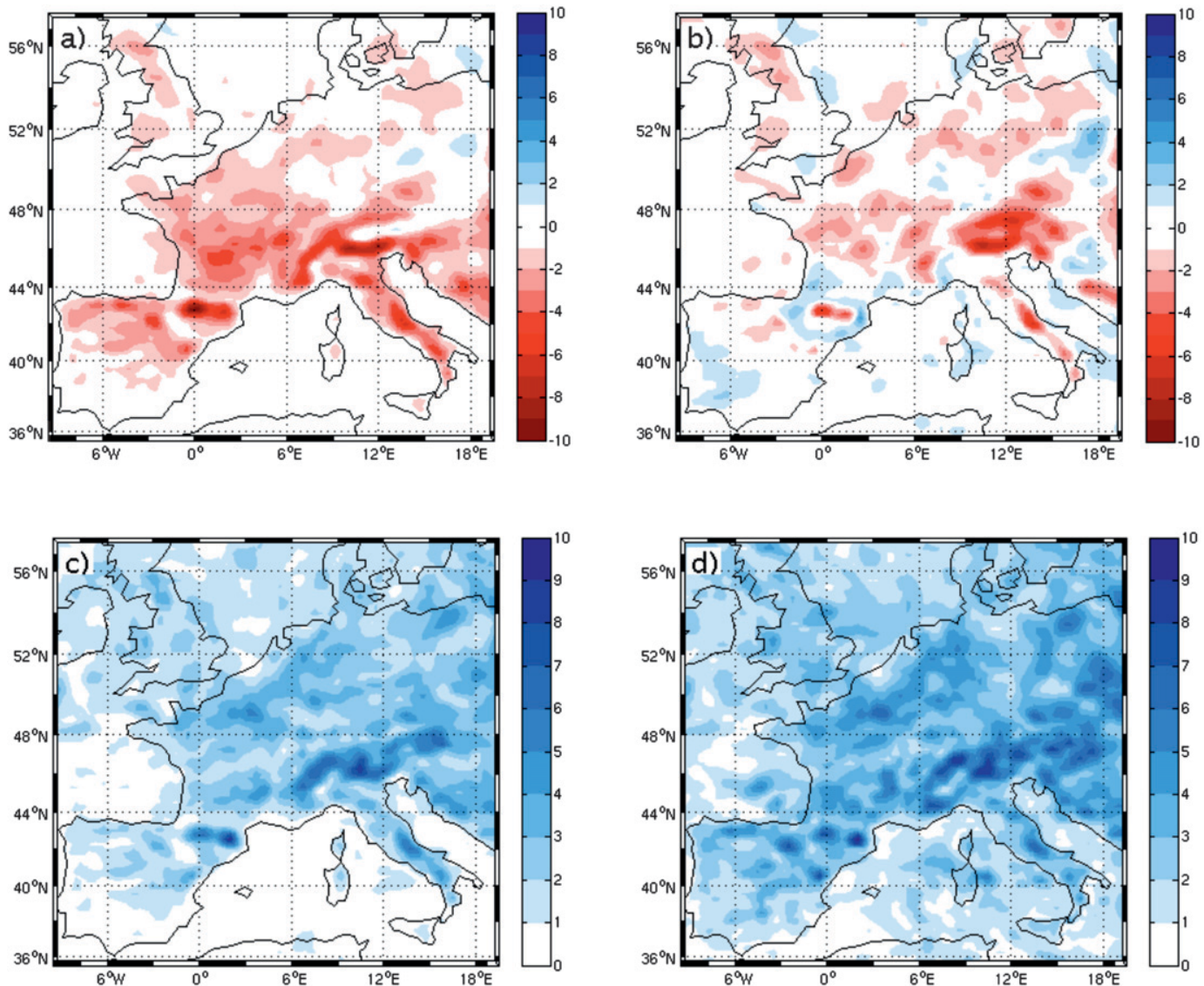

FIG. 6. Averaged total precipitation ( $\mathrm{cm}$ ) over the 10 hottest summers (a) DRY minus WET difference accumulated over the months of July and June; (b) the same, but for the difference between July and June. (c), (d) The standard deviation of the variables plotted in (a) and (b), respectively.

cases the convective events are always more intense in the WET case, resulting in larger precipitation than in the DRY case.

\section{c. Impact on soil moisture}

Figure 8a shows the northward progression of the soil moisture anomaly. South of $46^{\circ} \mathrm{N}$, the initial DRY minus WET soil moisture differences tend to reduce with time, mainly because in the WET simulation the soil is drying up faster than in the DRY simulation. In the WET simulation, evapotranspiration is higher compared to the DRY one. In the DRY simulation, the soil is already initially very dry and cannot get more depleted in moisture. North of $46^{\circ} \mathrm{N}$, where no initial difference in soil moisture was prescribed, the opposite occurs; that is, in the DRY simulation the soil moisture is lost more rapidly through evaporation and plant transpiration than in the WET one. This behavior is found mainly in central France, as a result of the soil dryness anomaly propagating from the regions south of $46^{\circ} \mathrm{N}$ toward the western Alps.
The evolution of the DRY minus WET difference in soil moisture over the target area of northern France (Fig. 8b) shows, on average, an increasing soil moisture deficit in the DRY simulation as compared to the WET one. Exceptions are again years 1959 and 1992, when the soils are replenished with water after more convective rainfall events impact the DRY simulation relative to the WET one. The soil moisture response is quite similar to that of precipitation (Fig. 7). This similarity suggests that the principal variable controlling the northward displacement of drought (meaning the soil moisture deficit) is the precipitation anomaly, rather than the effects of temperature alone. If the drought south of $46^{\circ} \mathrm{N}$ decreases the precipitation, it is the precipitation anomalies that transport the drought to the north.

\section{d. Drought propagation over northern France}

The model sensitivity to the initial soil moisture anomaly in southern Europe depends on the details of the atmospheric circulation that characterized each of the 10 hottest summers. Figure 9a shows, for each 


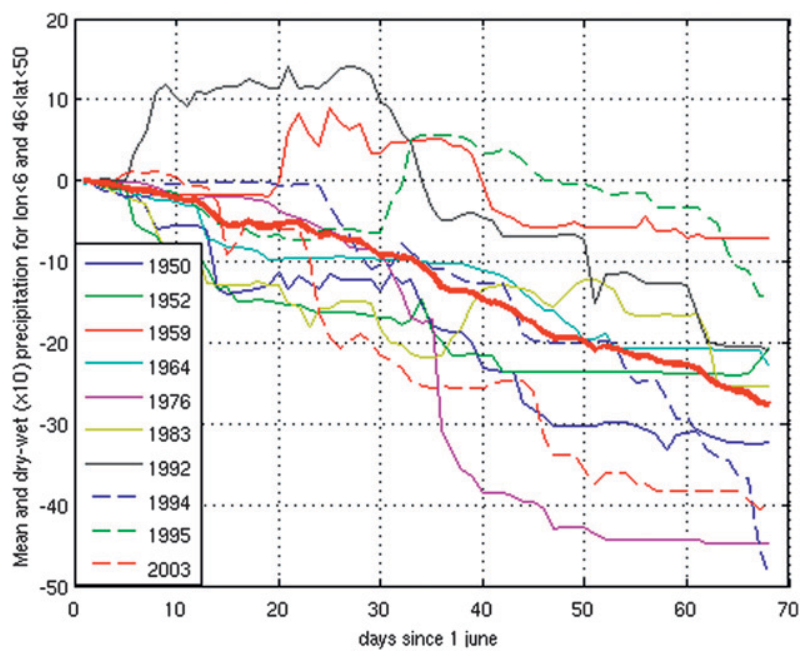

FIG. 7. Time evolution of the DRY minus WET differences of total accumulated precipitation $(\mathrm{cm})$ for each of the 10 hot summers, averaged over northern France, for the target area shown in Fig. 1. The red bold line represents the average of all the hot summers (see corresponding temperature evolutions in Fig. 5).

summer, the length scale (in degrees of latitude) of the soil moisture anomaly propagation north of $46^{\circ} \mathrm{N}$, defined as

$$
l=\frac{\sum_{i, j}\left(\mathrm{lat}_{i, j}-46\right) \Delta q_{i, j}}{\sum_{i, j} \Delta q_{i, j}},
$$

where lat is latitude and $\Delta q_{i, j}$ is the DRY minus WET soil moisture difference of each $(i, j)$ grid point within the target area in northern France (see Fig. 1). In the early days of June, at the beginning of the simulations, when the DRY minus WET differences in soil moisture are not well established, $l$ is not well defined and can be quite noisy. After some time, depending on the year, the drought propagation takes place, and after 2 months, it propagates northward by $2^{\circ}-3.5^{\circ}$ north of $46^{\circ} \mathrm{N}$. The summer seasons when conditions were most favorable for the propagation are in 1983 and 1994; note that the summer of 2003, although it was the strongest heat wave, does not show a high propagation. In fact in that case the soil moisture was already abnormally low at the beginning of the season in the northern area. These results are consistent with the simulations of Fischer et al. (2007a). On the contrary, 1959 and 1992 did not favor the northward propagation at all, as already discussed in the previous sections. They are omitted in Fig. 9a.

The relative evolution trajectory of the DRY minus WET soil moisture difference with respect to the DRY and WET mean during June and August is shown in Fig. $9 \mathrm{~b}$ for each summer. The initial soil moisture stands on the axis $x=0$ in Fig. 9b, and all of the integrations move toward the lower-left panel as time passes, because of the average seasonal drying and because of the response to the added DRY anomaly. On average, the soil is almost saturated at the beginning of each simulation; initially the wettest years are 1983, 1964, and 1992, all with volumetric soil moisture above $30 \%$. The initially driest years are 1959, 2003 and 1976, all of which have volumetric soil moisture below $26 \%$. In all cases the departures from the mean get more negative as time increases, and the drought increases in the northern region with more or less efficiency. On average 19\% more moisture ( $x$ axis of Fig. 9b) is lost by evapotranspiration in the DRY case with respect to the WET case, but the wilting point threshold, which ranges between 0.08 and 0.11 in the area, is not always attained by the end of July. At the end of July the DRY simulation produces volumetric soil
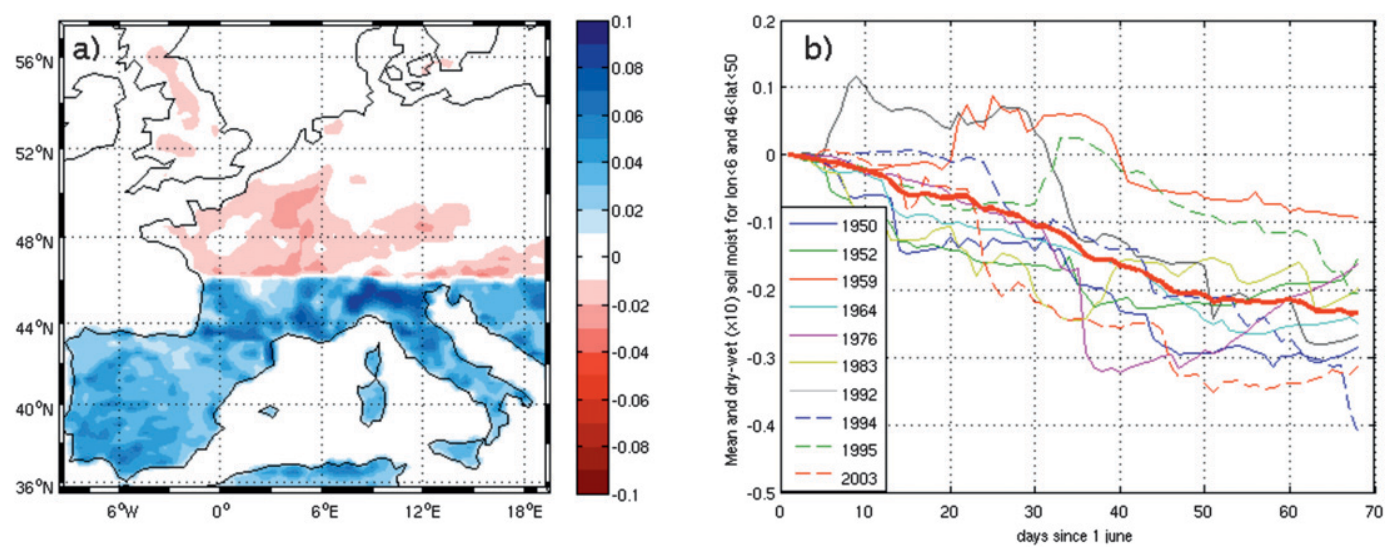

FIG. 8. (a) July minus June difference of the DRY minus WET field of the root layer (1 m) volumetric soil moisture content, in fraction of total volume. (b) Time evolution of the DRY minus WET soil moisture difference (multiplied by 10), spatially averaged over the target area of northern France (see Fig. 1). 

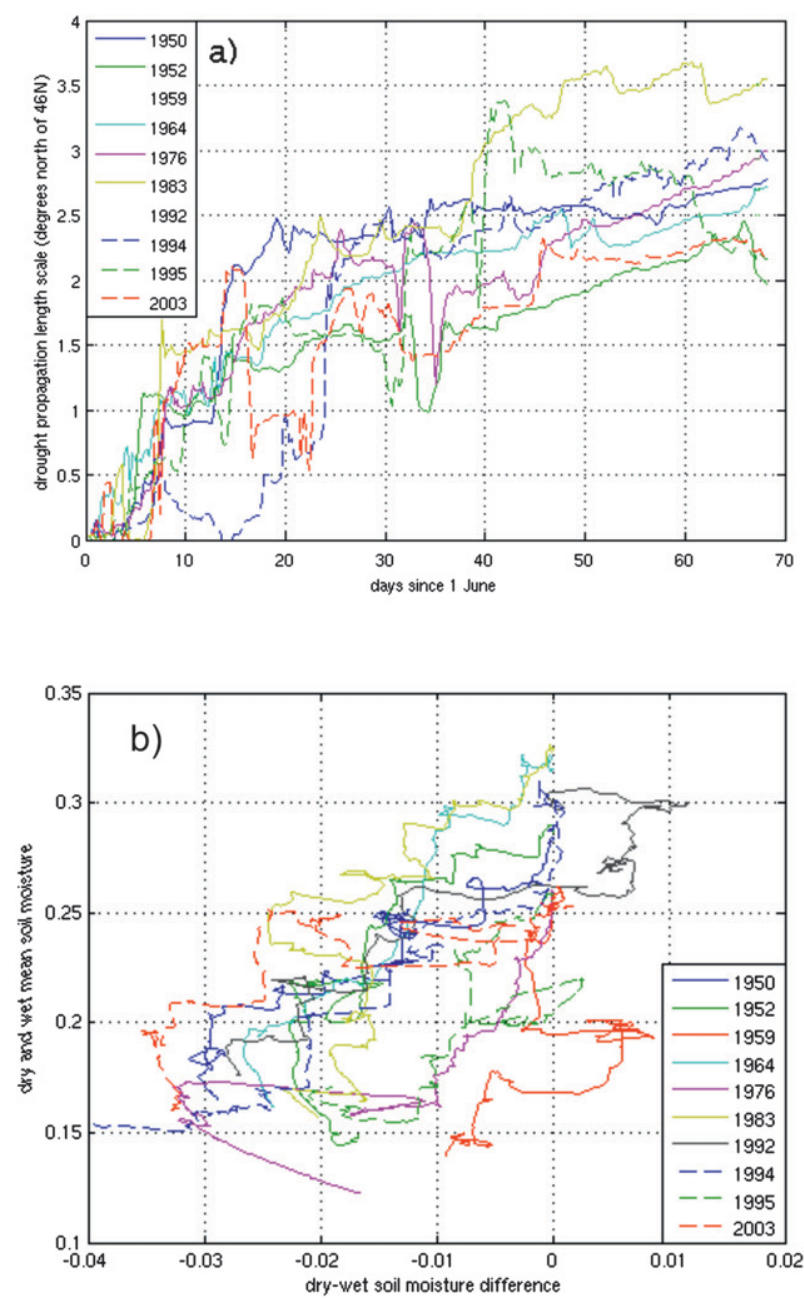

FIG. 9. (a) Length scale of the soil moisture anomaly propagation north of $46^{\circ} \mathrm{N}$ (computed over the target area of northern France showed in Fig. 1) for each of the 10 hottest summer; the cases of 1959 and 1992 are omitted (see text for details). (b) Relative time evolution during June and July of the DRY minus WET soil moisture difference vs the DRY and WET mean, averaged over the same area. The starting points have $0 x$ coordinates.

moisture below $13 \%$ in 1976,1994 , and 2003. In the other years values are between $13 \%$ and $14 \%$; the exceptions are 1959 and 1992, where the DRY simulation ends with around $15 \%$ volumetric soil moisture. The largest deficit in soil moisture relative to the mean is found by the end of July 1983, followed by 1964 .

\section{e. Surface energy budget and local effect}

The total (solar plus longwave) incoming surface radiation for DRY - WET July-June differences at the surface (Fig. 10a) is positive, on average. This results from reduced cloud cover (not shown) in the DRY simulations with respect to the WET ones. Reduced cloudiness itself can be driven by the following several mechanisms: less latent heat flux resulting from lower soil moisture (local effect), large-scale transport of drier and/or warmer air masses (transport effect), or increased vertical stability and more anticyclonic conditions leading to thicker boundary layers and reduced convection (synoptic effect).

From June to July, the increasing surface energy determined by decreasing cloudiness (Fig. 10a) results in more sensible heat and less latent heat production (Figs. 10b,c). The DRY minus WET July minus June latent heat difference is indeed negative in most of the northern area $\left(>46^{\circ} \mathrm{N}\right)$, while the sensible and latent heat fluxes DRY - WET differences are small but significant. In southern areas, the radiation flux difference is small because the weather is in any case not cloudy in both DRY and WET simulations. As drought increases in these areas, more incoming energy is used as sensible heat, with equally less used as latent heat.

A clear picture comes out of the mean time evolution of net radiation and heat fluxes, and the corresponding evolution of the Bowen ratio in the target area of northern France. This is illustrated in Figs. 11a-d. In this area, the anomalous cloudiness transport leads to higher radiation fluxes in the first days of integration, with the radiation anomaly being consistently positive starting from day 10 (Fig. 11a). This leads to higher temperatures resulting from sunnier weather conditions. During the first month, the sensible heat flux (Fig. 11d) does not change much between the WET and DRY cases. The Bowen ratio (sensible/latent flux ratio) decreases slightly (Fig. 11b), because the extra solar energy is converted into more latent heat (Fig. 11c) rather than into more sensible heat. Transpiration is enhanced by increased atmospheric dryness and by increased temperature. During the second month, the sensible heat flux positive difference increases, and the latent heat flux difference drops slightly. As soils dry further at the end of July, the Bowen ratio increases, inducing an imbalance in heat fluxes, with most of the extra solar energy being converted into sensible heat. Then the local effect becomes indeed more important.

\section{f. Synoptic effect}

The last significant effect of a southern European spring soil moisture deficit is its influence on the largescale synoptic circulation. Figure 12 shows the averaged DRY - WET differences of mean sea level pressure and geopotential height for the month of July. Because of the temperature increase, sea level pressure is lower over dry soils. In contrast, the 500 -hPa height is increased by $5 \mathrm{~m}$, giving more anticyclonic conditions over a large fraction of Europe. These response patterns are very similar to those obtained by Ferranti and Viterbo (2006). 

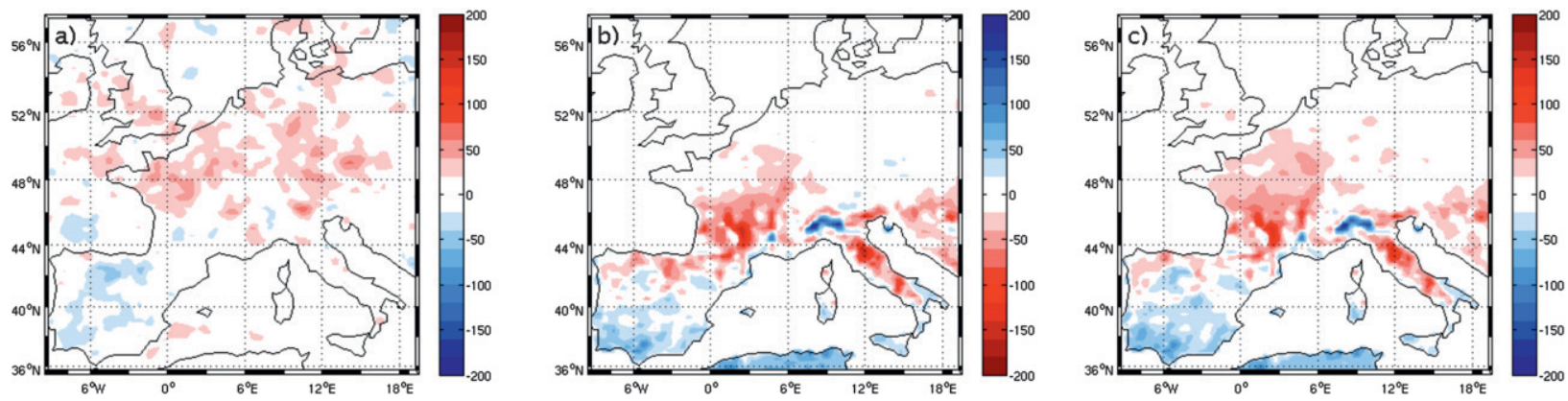

FIG. 10. (a) July minus June difference of the DRY minus WET field of total incoming radiation at $1200 \mathrm{UTC}\left(\mathrm{W} \mathrm{m}^{-2}\right.$ ). Same as (a), but for (b) the difference of surface latent heat flux and (c) sensible heat flux. The color scale in (b) is inverted with respect to (a) and (c), so that red colors correspond to smaller latent heat fluxes.

The daytime PBL height shows a marked increase (Fig. 12c), especially in southern Europe, where the DRY - WET difference of PBL height can reach values of the order of $1 \mathrm{~km}$. North of $46^{\circ} \mathrm{N}$, the DRY - WET difference of PBL height is less than $200 \mathrm{~m}$ and goes to zero farther to the north. This is in agreement with Schär et al. (1999), who showed how an enhanced Bowen ratio leads to higher boundary layers and reduced convection. Conversely, above the boundary layer, the static stability is decreased in the DRY simulation with respect to
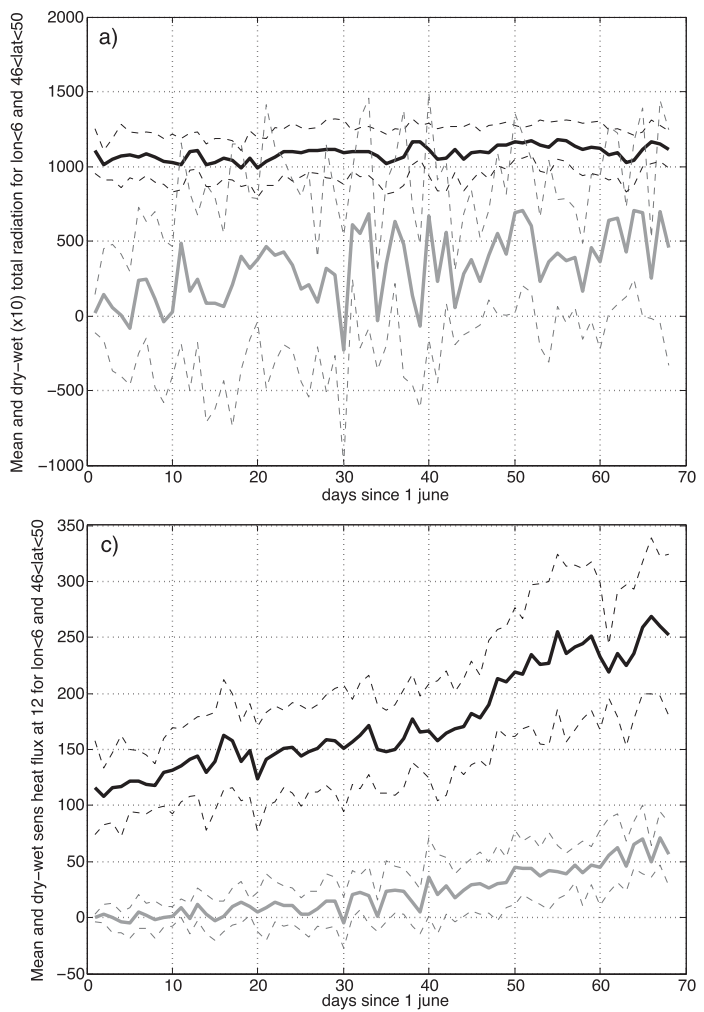

the WET one (Fig. 12d). In all of the maps shown in Fig. 12, the differences are statistically significant, with $95 \%$ confidence in a region similar to that covered by the geopotential height anomaly of Fig. 12b.

\section{Conclusions and discussion}

The challenge of understanding the regional impacts of climate change led to several studies trying to elucidate the mechanisms of summer heat waves, especially
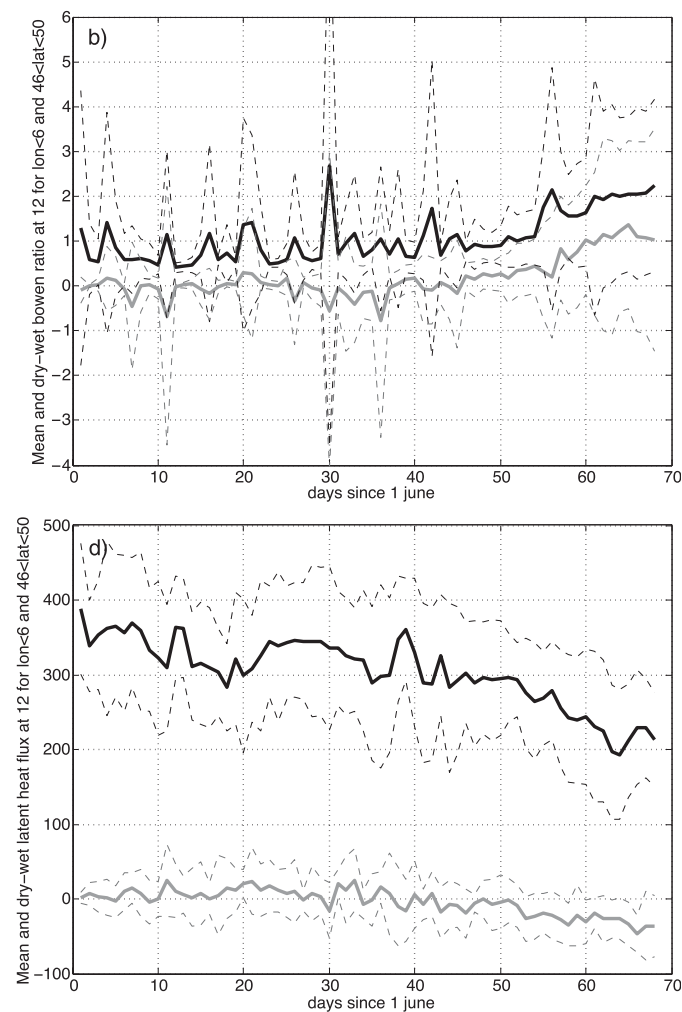

FIG. 11. Same as Fig. 5, but for (a) total net incoming radiation at the surface, (b) the Bowen ratio, defined as the ratio of sensible to latent heat fluxes, (c) sensible heat flux, and (d) latent heat flux. Differences of incoming radiation are multiplied by 10 for readability. 

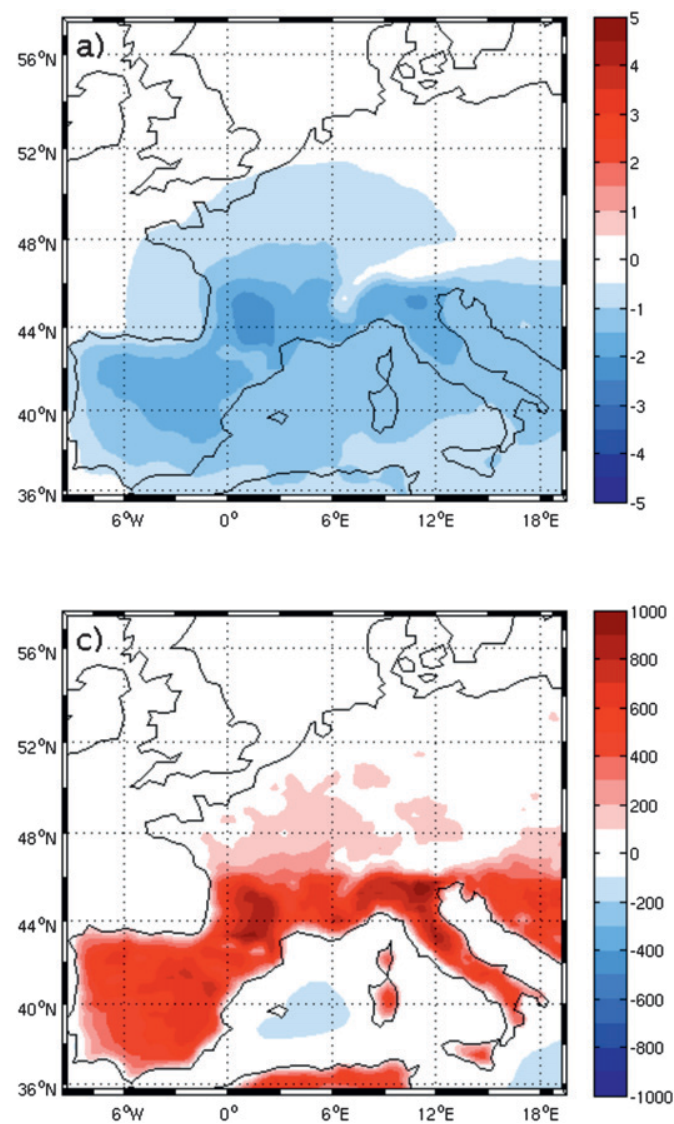
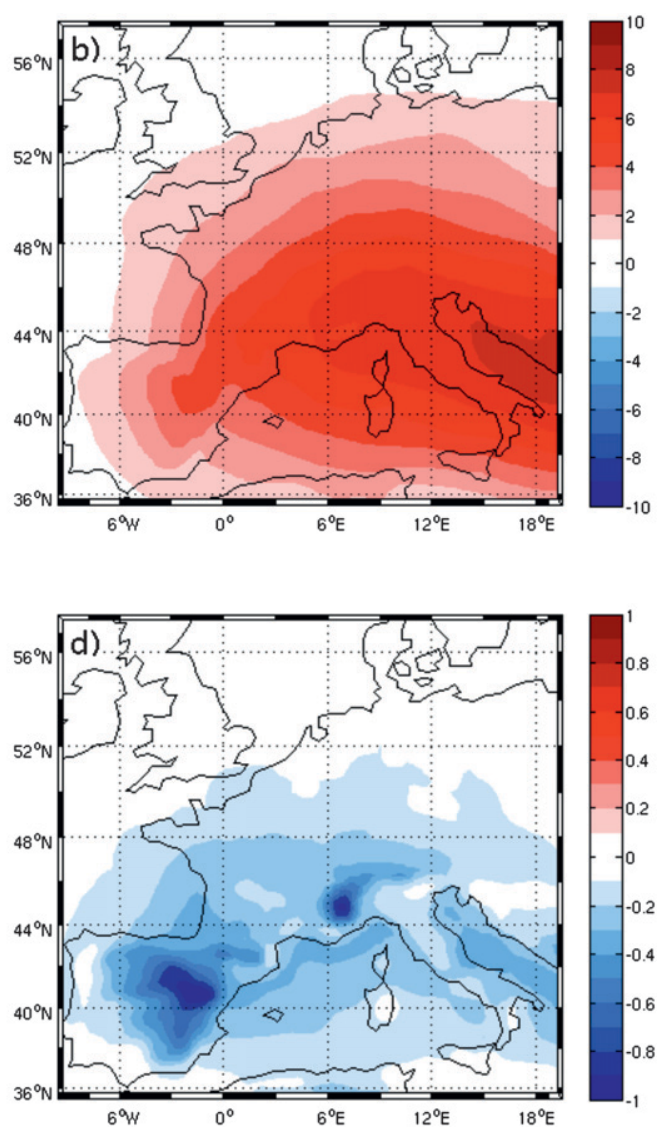

FIG. 12. DRY minus WET mean July anomaly of (a) mean sea level pressure (mb), (b) geopotential at $500 \mathrm{mb}(\mathrm{m})$, (c) boundary layer height at $1500 \mathrm{UTC}(\mathrm{m})$, and (d) lapse-rate between 700 and $500 \mathrm{mb}\left(\mathrm{K} \mathrm{km}^{-1}\right)$.

in Europe, since the unprecedented 2003 heat wave. This paper details the sequence of regional climate processes involved in the northward progression of heat and drought during summer, as initiated by drier spring conditions in southern Europe (Vautard et al. 2007). During the European hottest summers of the past $50 \mathrm{yr}$, interactions between the soil, ocean, and atmosphere amplified the drought intensity and extent. Anticyclonic conditions favor higher radiation, heating the continental and nearby oceanic surface. The persistence of warm temperatures heats the Mediterranean Sea surface, which responds by amplifying anticyclonic conditions and heat over Europe (Feudale and Shukla 2007). We identified three types of positive feedbacks related to soil moisture. Drier soils favor 1) higher sensible heat fluxes and subsequent local warming, 2) drier air with less and less extended clouds, leading to enhanced solar radiation, and 3) lesser convection, leading to increased PBL height and to the development of upper-air anticyclonic circulation conditions.

We analyzed the sequence of these feedbacks using numerical simulations with MM5. The model was integrated from early to midsummer for the 10 hottest summers of the past $50 \mathrm{yr}$. Our results show that a difference in initial soil moisture over southern Europe propagates northward. In early summer, an initially drier southern soil creates air masses that carry less humidity in the boundary layer. These drier air masses decrease cloudiness and convection over northern Europe, increase the evaporative demand, and help drought to further propagate. The displacement of the anomalously dry air is simply compatible with occasional southerly wind episodes (see also Vautard et al. 2007). In July, once the drought is established, drier soils in the north enhance locally sensible heat fluxes relative to latent heat fluxes, favoring an increase in surface temperature. These processes also increase anticyclonic conditions and atmospheric stability, inhibiting wet convection (but increasing dry convection and PBL heights) and favoring the establishment of stagnant weather.

A deeper knowledge of the mechanisms involved in the formation of temperature extreme events is necessary to quantify the importance of global climate change 
on regional conditions in Europe. We have shown that the importance of soil moisture feedbacks is crucial, and that these feedbacks can propagate at the continental scale. The next step is to investigate more in details the active role of the interactive vegetation and land use in summer drought.

Acknowledgments. The authors wish to thank Christophe Cassou, Masa Kageyama, Jan Polcher, Sonia Seneviratne, and Nicolas Viovy for useful discussions and suggestions. The research was partly supported by ANR Project ANR-05-blan-0223.

\section{REFERENCES}

Beniston, M., 2004: The 2003 heat wave in Europe: A shape of things to come? An analysis based on Swiss climatological data and model simulations. Geophys. Res. Lett., 31, L02202, doi:10.1029/2003GL018857.

Black, E., M. Blackburn, G. Harrison, B. Hoskins, and J. Methven, 2004: Factors contributing to the summer 2003 European heat wave. Weather, 59, 217-221.

Cassou, C., L. Terray, and A. S. Phillips, 2005: Tropical Atlantic influence on European heat waves. J. Climate, 18, 2805-2811.

Chang, F.-C., and J. M. Wallace, 1987: Meteorological conditions during heat waves and droughts in the United States great plains. Mon. Wea. Rev., 115, 1253-1269.

D'Andrea, F., A. Provenzale, R. Vautard, and N. De NobletDecoudré, 2006: Hot and cool summers: Multiple equilibria of the continental water cycle. Geophys. Res. Lett., 33, L24807, doi:10.1029/2006GL027972.

Della Marta, P. M., J. Luterbacher, H. Von Weissenfluh, E. Xoplaki, M. Brunet, and H. Wanner, 2006: Summer heat waves over Europe 1880-2003, their relationship to large scale forcing and predictability. Climate Dyn., 29, 251-275.

Dudhia, J. A., 1993: Nonhydrostatic version of the Penn StateNCAR Mesoscale Model: Validation tests and simulation of an Atlantic cyclone and cold front. Mon. Wea. Rev., 121, 1493-1513.

Ek, M. B., K. E. Mitchell, Y. Lin, E. Rogers, P. Grunmann, V. Koren, G. Gayno, and J. D. Tarpley, 2003: Implementation of Noah land surface model advances in the National Centers for Environmental Prediction operational mesoscale Eta model. J. Geophys. Res., 108, 8851, doi:10.1029/2002JD003296.

Fan, Y., and H. van den Dool, 2004: Climate Prediction Center global monthly soil moisture data set at $0.5^{\circ}$ resolution for 1948 to present. J. Geophys. Res., 109, D10102, doi:10.1029/ 2003JD004345.
Fernández, J., J. P. Montávez, J. Sáenz, J. F. González-Rouco, and E. Zorita, 2007: Sensitivity of the MM5 mesoscale model to physical parameterizations for regional climate studies: Annual cycle. J. Geophys. Res., 112, D04101, doi:10.1029/ 2005JD006649.

Ferranti, L., and P. Viterbo, 2006: The European summer of 2003: Sensitivity to soil water initial conditions. J. Climate, 19, 3659-3680.

Feudale, L., and J. Shukla, 2007: Role of Mediterranean SST in enhancing the European heat wave of summer 2003. Geophys. Res. Lett., 34, L03811, doi:10.1029/2006GL027991.

Fischer, E. M., S. I. Seneviratne, D. Lüthi, and C. Schär, 2007a: Contribution of land-atmosphere coupling to recent European summer heat waves. Geophys. Res. Lett., 34, L06707, doi:10.1029/ 2006GL029068.

— — — P. P. Vidale, D. Lüthi, and C. Schär, 2007b: Soil moisture-atmosphere interaction during the 2003 European summer heat wave. J. Climate, 20, 5081-5099.

Huang, J., H. van den Dool, and K. P. Georgakakos, 1996: Analysis of model-calculated soil moisture over the United States (1931-93) and application to long-range temperature forecasts. J. Climate, 9, 1350-1362.

Kalnay, E., and Coauthors, 1996: The NCEP/NCAR 40-Year Reanalysis Project. Bull. Amer. Meteor. Soc., 77, 437-471.

Mahrt, L., and M. Ek, 1984: The influence of atmospheric stability on potential evaporation. J. Climate Appl. Meteor., 23, 222-234.

Mitchell, T. D., and P. D. Jones, 2005: An improved method of constructing a database of monthly climate observations and associated high-resolution grids. Int. J. Climatol., 25, 693-712.

Schär, C., D. Lüthi, and U. Beyerle, 1999: The soil-precipitation feedback: A process study with a regional climate model. J. Climate, 12, 722-741.

— , P. L. Vidal, D. Lüthi, C. Frei, C. Häberli, M. A. Liniger, and C. Appenzeller, 2004: The role of increasing temperature variability in European summer heat waves. Nature, 427, 332-336.

Seneviratne, S. I., D. Lüthi, M. Litschi, and C. Schär, 2006: Landatmosphere coupling and climate change in Europe. Nature, 443, 205-209.

Vautard, R., and Coauthors, 2007: Summertime European heat and drought waves induced by wintertime Mediterranean rainfall deficit. Geophys. Res. Lett., 34, L07711, doi:10.1029/ 2006 GL028001.

Zhong, S., H.-J. In, X. Bian, J. Charney, W. Heilman, and B. Potter, 2005: Evaluation of real-time high-resolution MM5 predictions over the Great Lakes region. Wea. Forecasting, 20, 63-81.

Zobler, L., 1986: A world soil file for global climate modelling. NASA Goddard Institute for Space Studies Tech. Memo. $87802,32 \mathrm{pp}$. 